\title{
Personal Tutorage System for Schools in Pakistan: A Policy Proposal
}

\author{
Asma Tariq ${ }^{1}$, Dr Faraz Janan² \\ ${ }^{1}$ Cantt Public Boys High School, Peshawar, Pakistan \\ 2University of Lincoln, United Kingdom
}

Purpose Of The Document

The core objective of a school is to develop children for challenges ahead in life ahead by passing them through a well-developed mechanise process of teaching, learning and scholarship. While teaching helps them to grow academically, learning and scholarship are essential for personal development. In a participatory, progressive and tolerant society, the role of a teacher is to help children in becoming positively 'participating citizens' (Sociology and 1967, 1967). In Pakistan, there is a huge emphasis on examoriented quantitative teaching practices within government schools; however, the learning and scholarship aspect seems to have been largely left neglected. Currently, the only opportunity for a child to have a mentor-oriented learning experience within the school is through subject classes. Unfortunately, these classes do provide subject-specific guidance but does address after the overall development needs of a child, in particular: personal development, their trajectory in achieving their full potential, hitting learning objectives through the schooling experience and in developing ways of self-reflection (Miles, 1985; Syed et al., 2007a, 2007b). The paper is focused on proposing the Personal Tutorage system and structure in Pakistan, nevertheless, it can be implemented with minor revisions anywhere else in the world.

The purpose of the draft is to propose a system of Personal Tutorage to be introduced at the government schools in Pakistan. For the benefit of the intended political and bureaucratic audience, the authors have intentionally kept the discussion closely relevant to the very structure of the proposed system and have avoided unnecessary jargon, as well as a detailed literature review. The draft is by no means suggested as a final proposal and has a substantial room for updates and structural improvements. Please note that elements or resources within to furnish this proposal may not be at present available in schools. Here, the word Personal Tutor refers to a member of staff in a school, typically a teacher; tutees refer to the students.

The Personal Tutorage System

'Personal Tutorage' is the process of assigning students to members of academic staff, who can help, signpost and guide their 'tutees' to achieve their full potential by non-subject based mentoring sessions and periodic meetings. Personal tutorage is in place in higher education, as well as in some places at the college level; however, its implementation of the primary and secondary level of education is yet to be seen. Each student will be assigned a Personal Tutor, where a member of staff responsible for the personal tutorage

Contributions: The plan is proposed and structured by A. Tariq; F. Janan helped in drafting, refining and in furthering discussions of the proposal. 
will maintain a 'register of correspondence' with their personal tutees. A list of students with their personal tutees will be available with every class-teacher and with the school administration. Students will be required to meet their personal tutees in a one-to-one setting within a reasonable period of time (this proposal suggests 6 months in the first instance, hence 2 meetings in full academic year) to discuss their academic progress, attendance and personal circumstances affecting the academic progress such as stress, bullying, harassment, general wellbeing and family issues causing distractions. Personal Tutor will ask the student for additional meetings in the case of consistent absences from the school. Moreover, the student will have access to their Personal Tutors besides the fixed periodic meetings and can request a meeting. Tutors and tutees should be able to agree on a mutually convenient time for a meeting within a remit of 5 working days.

The key of success here is that because Personal Tutors are more simply learned, experienced and trained individuals as compared to the tutee, are well aware of the tutee's circumstances; therefore they are in a better position to give impartial advice and motivate a tutee in various aspects of their student life that requires attention. Tutors also guide students on the process involved in the school should they need any help, and are supposed to safeguard children in the event if they have any apprehensions about the school itself (such as harassment, discrimination due to faith, appearance, gender or social class etc.).

\section{Why 'Personal Tutorage'?}

Personal tutorage encourages students to become embedded in the learning process, to get inspired and plan for their future beyond schools. Personal tutorage keeps an eye on the student performance, arrange meetings to discuss issues causing stress, low attendance and low grades. A Personal Tutor helps in giving a sense of belonging to the tutee and support them to focus on their weaknesses. It also makes the student have confidence that someone in the school is looking after them in a personal capacity.

A Personal Tutor will be a steady point of contact for a student from class 1-5 and class 5 to 10 (Bullock and Wikeley, 2004a; Cottrell et al., 1994a; Standard and 2006, 2006a), where they are supported throughout the journey in their schools. If an issue arises, within reasonable circumstances, Personal Tutors can be changed.

Personal Tutors will be available if the student faces any issues that have academic or life-related implications. They will assist tutees in recognizing their strengths and weakness, to achieve their learning objectives within the school and help them in preparing short term plans to improve their academic skills (Practice and 2004, 2004). They will provide the opportunity for the students to reflect on their termly results and to think about their future assessments. They will encourage students to become ambitious about their career, to plan for potential subjects beyond school and to think about picking up professional role models.

Safegaurding The Most Vunerable Children

Many students in the government schools belong to under-privileged backgrounds, where they either do not have or have limited access to resources that can help them achieve their full potential (Amjad, Development 
and 2014, 2014; Aslam, 2007; Economics and 2009, 2009; Hazarika, Studies and 2003, 2003; Rahman, 2005; Review and 2000, 2000). Most of the students lose motivation in their journey through the primary education for a number of reasons, including but not limited to family issues, financial stress, anxiety, unaddressed bullying at school, verbal or physical abuse, sign positing to the available support and reasonable advice. Other issues may include emotional distress, feeling out of control, having to work as part-time child labour (economics and 2000, 2000), supporting the family financially by working in the evenings, loss of loved ones, isolation or drugs (Ning, Science and 2007, 2007; Syed et al., 2007b). Those students who fail to exploit the very purpose of schooling and are unable to achieve their ambitions, or do not show signs of personal and academic development could greatly benefit from the pastoral care (Schools and 1985,1985$)$ through personal tutorage.

It is very important that Personal Tutors identifies and notify the school of any mental health issues (Sociology and 1967, 1967) (Rahman et al., 1998), issues related to rare disorders or learning difficulties such as Autism or Dyslexia (Rahbar et al., 2011; Suhail, Research and 2008, 2008; Ullah et al., 2015; Yue, Management and 2010, 2010). The issues do not enjoy a good level of understanding and awareness in financially or socially under-privileged communities, thus a Personal Tutor should look out for any unusual traits and respond to them by arranging a parents meeting as well as by notifying the school. Every school must have a student wellbeing officer (Today and 2001, 2001) who can work closely with personal tutees, and who will keep a record of such students, and make sure these students are dealt with courtesy, integrity and with confidentially.

Students who perform exceedingly well in academics and personal wellbeing may not require personal tutorage but will be available to them if they need it.

\section{The Personal Tutor Role}

The purpose of Personal Tutorage (Gardner, health ... and 2010, 2010; Gidman et al., 2000; (Great ... and 1993, 1993) are to influence students, particularly the weak and most venerable, to achieve their full potential. The primary role of the Personal Tutor is to listen to the academic concerns of the student (Bullock and Wikeley, 2004b; Gardner, health ... and 2010, 2010; Practice and 2004, 2004), respond to their reports and offer academic advice, guidance and to look after the student wellbeing. The secondary role of the tutor is to listen to issues related to their personal circumstances that are directly linked to their academic performance and suggest reasonable advice. Any advice from a Personal Tutor is not binding on the student and will be dealt with utmost confidentiality (Ning, Science and 2007, 2007; Yue, Management and 2010, 2010) within the school environment. Any serious or criminal that require immediate intervention, for example, death threats to the student or a severe healthcare concern, will be reported without delay to the head of the school who will then notify it to the relevant authorities and parents. Personal Tutor will not deal with any authority outside the school preview unless otherwise summoned or asked by the school within a good reason.

Personal Tutor will develop a good relationship with the tutees, based on common curtsey and within the professional bounds. They will hold regular meetings where students will be encouraged to talk openly (Ning, Science and 2007, 2007; Schools and 1985, 1985) about their academic concerns and any difficulties 
they may have. Issues related to members of academic staff will be reported to the head of the school, the student wellbeing officer (if it applies) and/or a designated person. Students will have the opportunity to discuss their results and prepare a short-term plan to improve their performance.

Personal Tutor will summon the student for a meeting in the case of regular absentees from the school. The Personal Tutor will also summon the student if their grades are well below the average. However, it is not the responsibility of the Personal Tutor to keep track of the student attendance or their academic record, and a designated person from the school will notify the Personal Tutor to take action in such circumstances. Here, we will refer to the "designated person" as the senior tutor (Richardson and Wolfe, 2001)(Higher ... and 2018, 2018; Shipton, 1995). The role of the senior tutor is explained in the "Proposed Structure" section. Nevertheless, Personal Tutor is responsible for keeping the record of all meeting with their tutees in the correspondence register, especially the important meeting with where key concerns are raised and action plans are suggested. Such a record is vital to track the performance of the student. This record could be in the form of a note in the student file (if it applies in some schools) or in a register of Personal Tutorage supervised by the relevant personal tutee.

\section{The Proposed Structure}

There are several ways in which this Personal Tutorage system can be structured. However, we suggest the following as a starter for the process. This structure will go through iterations over the course of time, will be improved from experience, updated with changing demands, and could be adopted to the individual requirements of every school.

1. The Personal Tutorage structure consists of four pillars: 1) school administration; 2) senior tutor; 3) Personal Tutor; 4) the tutee (student).

2. The school administration will appoint/designate a Senior Tutor, who is a seasoned academic and is aware of the processes and systems in place at the school.

3. Senior Tutors are responsible for the coordination and providing support to the Personal Tutors. They are responsible for facilitating and supervising the Personal Tutorage system within the school from the administrative point of view. However, they are not able to influence the combination between a Personal Tutor and a tutee.

4. The school administration will also appoint a student wellbeing officer, who will be the focal point for the issues between the school and students. Some schools have this post in the form of Chief Proctor.

5. The Senior Tutor will assign tutees to all members of staff, where each staff can get a tutee from any level of the school, of any ability and from any subject. Senior Tutor will maintain the list of personal tutees and tutors over an academic year.

6. Senior Tutor will maintain the Personal Tutor Handbook, which will have rules and regulations for the Personal Tutor on how to deal with various circumstances. Such a handbook will be prepared by the Senior Tutor in consultation with the Student Wellbeing Officer and the school administration. The handbook also outlines with boundaries within which the Personal Tutor can 
operate with a student, as well as gives an understanding of various processes to support students within the school.

7. Senior Tutor will be notified by the class teachers if a student has regular absentees from the school and requires an intervention. Senior Tutor will then inform the Personal Tutor to arrange a meeting with the tutee and discuss any issues related to absentees.

8. Class Teachers will compose a list of weaker or failed students after each termly exam and provide it to the Senior Tutor, who will then notify Personal Tutors with a list of student they have to meet up with. A student will remain a personal tutee of a teacher from Class 1-5; then form Class 5-10.

9. Personal Tutors will have a 4-monthly one-to-one meeting with all their personal tutees. These meetings will be monitored and Time Tabled. If one-to-one meetings are a problem in large cohorts, schools can decide to have a meeting with small groups of personal tutees; and one-toone meetings with those students only who are in the dire need of improvement.

10. Personal Tutors will maintain a register of correspondence and keep a record of all their meetings with the personal tutees. A detailed record of the meeting that is of high concern or that involves action plans would be desirable.

11. Meetings between the Personal Tutor and the tutee should be confidential and can only be disclosed to the relevant people within the school set-up, such as the class-teacher, wellbeing officer and the Head of the school.

12. In exceptional circumstances within a reason, a tutee may ask to have their Personal Tutor changed. Senior Tutor will be responsible to assign another Personal Tutor to the tutee after having been satisfied with the reasons to do so.

13. Tutees may express concerns about their subject teachers to their Personal Tutors. These concerns are at least to be addressed within the meetings, or at best to be forwarded to the Senior Tutor and Head of the School.

14. Personal Tutor has a duty of conscious to safeguard their tutees in the event of unjustified practices within the school.

15. Students are responsible to manage their learning workload and cover the curriculum throughout the year. However, there could be extenuating circumstances that might prevent the tutee from completing a particular work or part/full academic term. These circumstances are not taken into account. A tutee should bring these into the notice of the Personal Tutor, who can then assess these circumstances and make recommendations to the school in favour of the student's request. The authority to whether or not to accept these recommendations lies with the senior school administration, however, such a review of requests will help the administration in making a certain decision.

16. The students should clearly know how to contact the Personal Tutor. If they request a meeting, the Personal Tutor should be able to arrange a meeting within 5 working days. If the Personal Tutor is not able to respond for any reason, the student should be able to contact the Senior Tutor.

17. The school should draw realistic boundaries for the behaviour and expectations of personal tutees.

18. Personal Tutor should have a record of all their weak tutees and indicative action plan or note on what was suggested to improve the tutees academic standing. If a tutee does not respond to the action plan, this should also be noted in the register.

19. In a Personal Tutoring meeting: 
a. A Personal Tutor should calmly and carefully listen to their tutee(s) before suggesting any advice or chalking out an action plan.

b. A Personal Tutor cannot sway a tutee to confess or convey the tutor's words.

c. A Personal Tutoring session is a conversation in the interest of the tutee and not an interview. It should be carried out without pressuring the tutee. The aim of the meeting is to understand the tutee's circumstances and to advise on how to improve things, to motivate and inspire, rather than to judge and intimidate.

d. A Personal Tutoring meeting may trigger for an immediate intervention by the school, should severe healthcare or criminal concern arise. The decision to intervene can only be taken by the Head of the School or the parents of the tutee or both.

e. All communication in the Personal Tutoring sessions are confidential and will only be shared with the relevant people within the school on a need-to-know basis.

f. All meetings will be recorded in the registered with a brief note and/or keywords for action plans, with date, time and place.

g. If a student without a good reason does not show up for a meeting, personal tutee should report them to the school administration.

\section{Workload Scheduling}

Personal Tutorage system is vital for the personal and academic development of the students, however, it comes with a workload cost. In large cohorts, these meetings will be time-consuming, and therefore the workload allocation process within the schools will have to take into account an indicative amount of time taken by the process for assessing the workload of individual members of staff. The school should have strict policies in place to take action if the Personal Tutor is harassed, threatened or bullied by a tutee for any reason. The school will have to make sure the safety and security of Personal Tutors in any case.

\section{Support For Staff}

The process of Personal Tutorage seems less complex, however, to ensure the highest productivity school will have to arrange short induction seminars to train its members of staff for Personal Tutorage. It can be thought-out and discussed at a later stage on how these training can be assured as per estaiblished the practices (Cottrell et al., 1994b; (Great ... and 1993, 1993; Newton, Today and 1998, 1998; Practice and 2004, 2004; Standard and 2006, 2006a, 2006b).

\section{Reflections And Review}

The school will conduct a local audit and compile a report on the effectiveness of the Personal Tutorage system by the end of each year. The audit will show how many students were identified with learning difficulties during the year, and how many had improved over time. It will also look into any serious issues arises during the year and how the school had dealt with it. It will review the support available to the students and how to assess the needs of the school in the student wellbeing context. This report will help to reflect upon the Personal Tutorage system in place at the school and will help in making 
recommendations on how to improve it. Such a report should be available to the external inspectors during an annual inspection process.

\section{References}

Amjad, R., Development, G.M.-I.J. of E. and 2014 (2014) 'Academic effectiveness of private, public and private-public partnership schools in Pakistan'

Aslam, M. (2007) 'The relative effectiveness of government and private schools in Pakistan: Are girls worse off?'

Bullock, K. and Wikeley, F. (2004a) 'Whose Learning?: The Role of the Personal Tutor'

Bullock, K. and Wikeley, F. (2004b) 'Whose Learning?: The Role of the Personal Tutor'

Cottrell, D.J., McCrorie, P., Education, F.P.-M. and 1994 (1994a) 'The personal tutor system: an evaluation'

Cottrell, D.J., McCrorie, P., Education, F.P.-M. and 1994 (1994b) 'The personal tutor system: an evaluation'

Economics, M.A.-E. and 2009 (2009) 'The relative effectiveness of government and private schools in Pakistan: are girls worse off?'

economics, R.R.-J. of population and 2000 (2000) 'Analysis of child labour in Peru and Pakistan: A comparative study'

Gardner, L.D., health ..., H.L.-J. of psychiatric and mental and 2010 (2010) 'Exploring the personal tutor-student relationship: an autoethnographic approach'

Gidman, J., Humphreys, A., Today, M.A.-N.E. and 2000 (2000) 'The role of the personal tutor in the academic context' (Great ..., A.C.-N. standard (Royal C. of N. and 1993 (1993) 'The personal tutor: a teacher's view.'

Hazarika, G., Studies, A.B.-T.J. of D. and 2003 (2003) 'Schooling costs and child work in rural Pakistan'

Higher ..., B.W.-Imp.T.U. of L.J. of and 2018 (2018) 'A Defining Moment for Personal Tutoring: Reflections on Personal Tutor Definitions and their Implications'

Miles, M. (1985) 'Children with Disabilities in Ordinary Schools: An Action Study of Non-Designed Educational Integration in Pakistan.'

Newton, A., Today, L.S.-N.E. and 1998 (1998) 'Practice placement supervision: the role of the personal tutor' Ning, J., Science, B.X.-A. in P. and 2007 (2007) 'Underconfidence-with-Pratice Effect for Judgments of Learning' Practice, S.H.-N.E. in and 2004 (2004) 'The mentoring role of the personal tutor in theFitness for practice'curriculum: an all Wales approach'

Rahbar, M.H., Ibrahim, K., Disorders, P.A.-... A. and D. and 2011 (2011) 'Knowledge and attitude of general practitioners regarding autism in Karachi, Pakistan'

Rahman, A., Mubbashar, M.H., Gater, R., Lancet, D.G.-T. and 1998 (1998) 'Randomised trial of impact of school mental-health programme in rural Rawalpindi, Pakistan'

Rahman, T. (2005) 'Passports to privilege: The English-medium schools in Pakistan'

Review, R.R.-T.W.B.E. and 2000 (2000) 'Child labor, child schooling, and their interaction with adult labor: Empirical evidence for Peru and Pakistan'

Richardson, L.D. and Wolfe, M. (2001) 'Principles and practice of informal education: Learning through life'

Schools, M.M.-C. in the and 1985 (1985) 'A teacher's view of Logo: from theory to practice'

Shipton, G. (1995) 'Personal tutoring in action: a handbook for staff who work with and support students'

Sociology, M.S.-T.B.J. of and 1967 (1967) 'Education and college culture'

Standard, A.D.-H.-N. and 2006 (2006a) 'Personal tutor encounters: understanding the experience.'

Standard, A.D.-H.-N. and 2006 (2006b) 'Personal tutor encounters: understanding the experience.'

Suhail, K., Research, F.Z.-P.J. of P. and 2008 (2008) 'Prevalence of autism in special education schools of Lahore'

Syed, E.U., Hussein, S.A., psychiatric ..., S.M.-S. psychiatry and and 2007 (2007a) 'Screening for emotional and

behavioural problems amongst 5-11-year-old school children in Karachi, Pakistan'

Syed, E.U., Hussein, S.A., psychiatric ..., S.M.-S. psychiatry and and 2007 (2007b) 'Screening for emotional and

behavioural problems amongst 5-11-year-old school children in Karachi, Pakistan'

Today, J.G.-N.E. and 2001 (2001) 'The role of the personal tutor: a literature review'

Ullah, S., Aqdas, I.M., Khan, N., Nabi, G., Medical ..., T.A.-U.J. of and 2015 (2015) 'Awareness Regarding Autism in

Schools' Teachers at District Lower Dir, Khyber Pakhtunkhwa, Pakistan'

Yue, S., Management, T.A.-E.T. and and 2010 (2010) 'Constructing three-in-one teaching system, improving students' innovation and pratice abilities' 